\title{
PENINGKATAN KONSENTRASI BELAJAR MAHASISWA MELALUI PEMANFAATAN EVALUASI PEMBELAJARAN QUIZIZZ PADA MATA KULIAH KIMIA FISIKA I
}

\author{
Leony Sanga Lamsari Purba \\ leony.purba@uki.ac.id \\ Universitas Kristen Indonesia
}

\begin{abstract}
This research is a descriptive qualitative study to determine the increase in student learning concentration through the use of quizizz learning evaluations in Physics Chemistry I. The population in this study were all Chemistry Education Students FKIP-UKI, with student sampling in the 3rd semester of the 2018/2019 academic year. Questionnaires that are used as instruments in research are validated by two validators who are experts in the field of learning evaluation. The results of data analysis obtained from the pre-test and post-test showed an increase in the concentration of student learning through the utilization of quizizz learning evaluations in Chemistry Physics I courses of 0.45, with a moderate increase in interpretation. Of the five indicators of learning concentration, the indicator of accuracy experienced the highest increase of 0.53 and the understanding indicator experienced the lowest increase of 0.36. Based on indepth interviews with students used as sampling, accuracy increases due to time constraints and students 'fear of the response of answers inputted by students to quizizz. Evaluation of learning using quizizz helps improve students' learning concentration. The use of quizizz can be done by other lecturers, teachers and students who will implement PKM to support the 4.0 industrial revolution.
\end{abstract}

Keywords: concentration, education, industry 4.0, physical chemistry, dan quizizz

\begin{abstract}
ABSTRAK
Penelitian ini merupakan penelitian kualitatif deskriptif untuk mengetahui peningkatan konsentrasi belajar mahasiswa melalui pemanfaatan evaluasi pembelajaran quizizz pada mata kuliah Kimia Fisika I. Populasi dalam Penelitian ini adalah seluruh mahasiswa Pendidikan Kimia FKIP-UKI, dengan sampling mahasiswa Semester 3 tahun ajaran 2018/2019. Angket yang digunakan sebagai instrument dalam penelitian di validasi oleh dua orang validator yang ahli dibidang evaluasi pembelajaran. Hasil analisis data yang diperoleh dari pre-test dan post-test menunjukkan terjadi peningkatan pada konsentrasi belajar mahasiswa melalui pemanfaatan evaluasi pembelajaran quizizz pada mata kuliah Kimia Fisika I sebesar 0,45, dengan interpretasi peningkatan sedang. Dari lima indikator konsentrasi belajar, indikator ketelitian mengalami peningkatan tertinggi yaitu sebesar 0,53 dan indikator pemahaman mengalami peningkatan paling rendah yaitu 0,36 . Berdasarkan wawancara mendalam terhadap mahasiswa yang digunakan sebagai sampling, ketelitian meningkat akibat adanya batasan waktu dan ketakutan mahasiswa terhadap respon jawaban yang diinput mahasiswa pada quizizz. Evaluasi pembelajaran dengan menggunakan quizizz membantu meningkatkan konsentrasi belajar peserta didik. Penggunaan quizizz dapat dilakukan oleh dosen pengampu matakuliah lain, guru dan mahasiswa yang akan melaksanakan PKM untuk mendukung revolusi industri 4.0.
\end{abstract}


Kata Kunci: konsentrasi, pendidikan, industri 4.0, kimia fisik, dan quizizz

\section{PENDAHULUAN}

Revolusi Industri 4.0 adalah sebuah tantangan dalam seluruh bidang ilmu, secara khusus dalam bidang pendidikan. Menurut Hamida (2013), Perkembangan IImu Pengetahuan dan Teknologi (IPTEK) mendorong setiap individu untuk selalu kreatif dan aktif dalam potensi diri. Untuk mengembangkan seluruh potensi diri mahasiswa baik secara kognitif, afektif, dan psikomotorik maka harus melalui proses belajar dalam dunia pendidikan(Purba, 2017)

Dalam proses pembelajaran kimia, pemanfaatan IPTEK sangat relevan sehubungan dengan materi kimia yaang kebanyakan abstrak di mana kimia yaitu sebagai produk (pengetahuan kimia yang berupa fakta, konsep, prinsip, hukum, dan teori) dan kimia sebagai proses (kerja ilmiah). Selain dalam proses pembelajaran, proses evaluasi pembelajaran juga menjadi fokus pendidik dalam pelaksanaan pengajaran dengan menerapkan kurikulumKerangka Kualifikasi Nasional Indonesia(KKNI). Sesuai dengan tuntutan kurikulum $\mathrm{KKNI}$ dan revolusi industri 4.0, pendidik harus mampu menciptakan pembelajaran yang kreatif, yang mampu menciptakan suasana pembelajaran yang efektif agar konsentrasi belajar mahasiswa dalam upaya mencapai standar mutu pendidikan. Standar Nasional Pendidikan Tinggi adalah satuan standar yang meliputi Standar Nasional Pendidikan, ditambah dengan Standar Nasional Penelitian dan Pengabdian kepada Masyarakat (Permenristekdikti No.44)

Terdapat beberapa metode pembelajaran yang dapat digunakan untuk meningkatkan konsentrasi belajar mahasiswa. Salah satu metode pembelajaran tersebut adalah e-learning. Pembelajaran berbasis e-learning dan jaringan pembelajaran elektronik atau e-learning telah dimulai pada tahun 1970-an (Waller dan Wilson, 2001) yang secara global konsep pembelajaran berbasis komputer dan jaringan sering kali diartikan sebagai e-learning. Elearning melayani proses belajar mengajar dan evaluasi pembelajaran dengan berbasiskan komputer, bahkan pada revolusi industri 4.0 ini lebih banyak memanfaatkan android.

Salah satu media evaluasi pembelajaran berbasis e-learning adalah dengan menggunakan quizizz. Media evaluasi pembelajaran Quizizz juga memberikan data dan statistik tentang kinerja mahasiswa, bahkan bisa mendownload statistik ini dalam bentuk spreadsheet Excel. Dosen dapat melacak jumlah jawaban mahasiswa.Pemanfaatan quizizz membantu pendidik dalam melakukan evaluasi tanpa dibatasi tempat, tampilan yang menarik dan pengaturan waktu yang diatur menuntun konsentrasi mahasiswa. 
"According to testing the implementing of Quizizz by researcher during the Arabic skill classroom, found that all students were very active to answer the questions which provided by researches, and more concentrated on the topic. And the results of the questioners shows that the students displayed the position attitude for quizizz as a online teaching and assessment tool during the Arabic class". (Suo Yan mei, 2018)

Penelitian Darmaningrat dengan judul Pemanfaatan Aplikasi Digital Learning pada Pembelajaran Pengayaan Di Sekolah Menengah Kota Surabaya, disimpulkan bahwa kemampuan untuk membuat rencana pembelajaran yang baik dan implementatif, mempraktikkan metode pembelajaran yang lebih variatif dan menarik, memperoleh sumber belajar yang lengkap dan memanfaatkan multimedia, serta mendokumentasikan aktivitas belajar dan sumber belajar yang digunakan dengan baik. Dengan memanfaatkan aplikasi ini, siswa memiliki kemudahan dalam mengakses sumber belajar yang interaktif dan menyenangkan. Selain itu, orang tua juga dapat aktif berpartisipasi dalam memantau materi yang disampaikan oleh para guru di sekolah.(Darmaningrat, 2018)

Penelitian Hasanah (2014) dengan judul Konsentrasi Belajar Pada Kegiatan Origami Dengan Menggunakan Metode Demonstrasi Pada Anak Kelompok B Di Tk Aba Gedongkiwo Kecamatan Mantrijeron Yogyakarta menunjukan konsentrasi anak pada kegiatan origami dengan menggunakan metode demonstrasi masuk pada kategori sangat baik. Indikator konsentrasi belajar yang tertingggi adalah indikator aktif dalam melakukan kegiatan, sebagian besar atau 93,10\% dari keseluruhan anak masuk dalam kategori sangat baik. Indikator menjawab pertanyaan sebesar $72,41 \%$ masuk dalam kategori sangat baik. Indikator antusiasme dalam mengikuti kegiatan, sebesar $68,96 \%$ anak masuk dalam kategori sangat baik. Indikator memperhatikan dan mendengar penjelasan guru sebesar 67,24\% anak masuk kategori sangat baik. Indikator melakukan kegiatan sesuai petunjuk guru sebesar $63,79 \%$ anak masuk dalam kategori sangat baik. Indikator respon verbal sebesar $55,17 \%$ dari keseluruhan anak masuk dalam kategori sangat baik. Jika dilihat secara keseluruhan konsentrasi belajar anak kelompok B di TK ABA Gedongkiwo dalam kegiatan demonstrasi maka sebesar $72,41 \%$, berada pada kategori sangat baik. 25,86\% pada kategori baik, dan 1,73\% pada kategori kategori cukup.

Untuk mengetahui peningkatan konsentrasi mahasiswa melalui pemanfaatan evaluasi pembelajaran quizizz pada mata kuliah Kimia Fisika I, dilakukan uji coba media evaluasi pembelajaran quizizz pada pembelajaran.

Belajar dilakukan manusia seumur hidupnya, kapan saja dan di mana saja dan waktu tidak ditentukan sebelumnya.Sekalipun demikian, belajar dilakukan manusia senantiasa pasti mempunyai tujuan dan maksud tertentu.ketika ada interaksi antara individu dan 
lingkungan, baik lingkungan fisik maupun lingkungan sosial hal tersebut adalah belajar. Lingkungan fisik adalah buku, alat peraga, dan alam sekitar. Saat orang belajar, responnya menjadi kuat, apabila ia tidak belajar responnya menurun. Dalam belajar ditemukan kesempatan terjadinya peristiwa yang menimbulkan respon belajar, respon pembelajaran, konsekuensi yang bersifat menguatkan respon tersebut (Hamalik, 2004).

Pembelajaran adalah usaha membentuk tingkah laku yang di inginkan. Pembelajaran sebagai cara pendidik memberikan kesempatan kepada peserta didik untuk berpikir agar mengenal dan memahami sesuatu yang sedang dipelajari (Darsono, 2004). Pembelajaran juga memberikan kebebasan kepada peserta didik untuk memilih bahan pelajaran dan cara mempelajarinya sesuai dengan kemampuannya (Sugandi, 2004). Pembelajaran merupakan setiap upaya yang sistematik dan sengaja untuk menciptakan agar terjadi kegiatan interaksi edukatif antara dua pihak, yaitu antara peserta didik (warga belajar) dan pendidik (sumber belajar) yang melakukan kegiatan membelajarkan (Sudjana, 2004). Pembelajaran adalah suatu usaha untuk membuat peserta didik belajar dan suatu kegiatan untuk membelajarkan. Disimpulkan bahwa pembelajaran adalah suatu upaya yang dilakukan untuk menciptakan proses belajar mengajar.

Pembelajaran di sini lebih menekankan pada bagaimana upaya pendidik untuk mendorong atau memfasilitasi peserta didik dalam belajar terutama untuk memotivasi peserta didik dalam belajar (Warsita, 2008).

Kimia adalah ilmu yang mempelajari komposisi dan sifat-sifat suatu benda serta perubahan dan pembentukan zat itu. Benda disebut juga dengan materi, yaitu segala sesuatu yang memiliki massa dan memiliki ruang.

Pembelajaran kimia dapat terlaksana dengan baik dengan adanya interaksi pembelajaran yang menarik antara pendidik dan peserta didik. Keberhasilan dalam mencapai tujuan pembelajaran sangat dipengaruhi oleh beberapa faktor, misalnya, konsentrasi belajar. Indikator atau alat mengukur konsentrasi dalam belajar yang dikemukakan oleh Super dan Crities yang dikutip oleh Kuntoro (dalam Rachman, 2010) antara lain sebagai berikut:

a. Memperhatikan setiap materi pelajaran yang disampaikan pendidik

b. Dapat merespon dan memahami setiap materi pelajaran yang diberikan

c. Selalu bersikap aktif dengan bertanya dan memberikan argumentasi mengenai materi pelajaran yang disampaikan pendidik

d. Menjawab dengan baik dan benar setiap pertanyaan yang diberikan pendidik

e. Kondisi kelas tenang dan tidak gaduh saat menerima materi pelajaran. 
Untuk mengukur tingkat konsentrasi belajar peserta didik, yang terpenting adalah mengetahui seberapa jauh individu tersebut menerima, menolak, menghindari setiap pelaksanaan pembelajaran yang menjadi kecenderungannya. Pembelajaran Berbasis elearning dan Jaringan Pembelajaran elektronik telah dimulai pada tahun 1970-an (Waller and Wilson, 2001) konsep pembelajaran berbasis komputer dan jaringan adalah suatu bentuk model pembelajaran dengan memanfaatkan teknologi web dan internet.Tujuan umum digunakan e-Learning dalam sistem pembelajaran adalah untuk memperluas akses pendidikan kemasyarakat luas, serta dalam rangka meningkatkan mutu belajar. Dunia pendidikan di Kanada dan Amerika misalnya bahkan telah mulai mengaplikasikan system ini pada dunia pendidikannya dan mucul komunitas-komunitas situs e-learning yang bersifat terbuka untuk diakses siapa saja.Sedangkan di dalam negeri pembelajaran menggunakan konsep ini sepertinya masih terbatas.

Quizizz adalah aplikasi pendidikan berbasis game, yang membawa aktivitas multi pemain ke ruang kelas dan membuatnya di kelas latihan interaktif dan menyenangkan. Dengan menggunakan Quizizz, peserta didik dapat melakukan latihan di dalam kelas pada perangkat elektronik mereka. Tidak seperti itu aplikasi pendidikan lainnya, Quizizz memiliki karakteristik permainan seperti avatar, tema, meme, dan musik menghibur dalam proses pembelajaran. Quizizz juga memungkinkan peserta didik untuk saling bersaing dan memotivasi mereka belajar. Peserta didik mengambil kuis pada saat yang sama di kelas dan melihat peringkat langsung mereka di papan peringkat. Instruktur dapat pantau prosesnya dan unduh laporan ketika kuis selesai untuk mengevaluasi kinerja peserta didik. Menggunakan ini aplikasi membantu merangsang minat dan meningkatkan konsentrasipeserta didik.

\section{METODOLOGI PENELITIAN}

Penelitian ini dilaksanakan pada bulan november semester genap tahun ajaran 2018/2019.Pada uji coba media evaluasi pembelajaran quizizz, populasi penelitian adalah seluruh mahasiswa Pendidikan Kimia, Fakultas Keguruan dan Ilmu Pendidikan (FKIP), Universitas Kristen Indonesia (UKI). Sampling dipilih dengan metode purposive sampling, yaitu mahasiswa angkatan 2017 yang sedang mengikuti perkuliahan kimia fisika I.

Penelitian ini menggunakan metode kualitatif dengan Rancangan penelitian yang digunakan adalah: one group pre-nontest post-nontest design. Rancangan tersebut dapat dilihat pada tabel 3.1 di bawah ini

\section{Tabel Rancangan Penelitian}

Pre-nontest Perlakuan Post-nontest




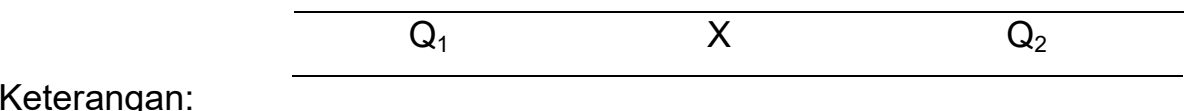

Keterangan:

$\mathrm{Q}_{1} \quad$ : Pre-nontest

$\mathrm{Q}_{2} \quad$ : Post-nontest

$\mathrm{X} \quad$ : Perlakuan

Berdasarkan rumusan masalah penelitian ini terdiri dari dua variabel bebas dan terikat, yakni meliputi media evaluasi pembelajaran quizizz (X) dan konsentrasi belajar mahasiswa(Y). Instrumen penelitian yang digunakan dalam penelitian ini berupa angket yang dibuat sendiri oleh peneliti dimaksudkan untuk menghasilkan data yang akurat yaitu dengan menggunakan skala Likert. Sugiyono (2014) menyatakan bahwa skala likert digunakan unutk mengukur suatu sikap, pendapat dan persepsi seseorang atau sekelompok orang tentang suatu fenomena sosial. Nana Sudjana (2004) menyatakan bahwa "variabel adalah ciri atau karateristik dari individu, objek, peristiwa yang nilainya bisa berubah-ubah". Penelitian ini melibatkan variabel konsentrasi belajar yang diberi perlakuan pada objek penelitian kemudian diperlihatkan adakah perubahan setelah perlakuan atau tidak. Adapun operasional variabel adalah:

\section{Tabel Kisi-Kisi Kuesioner Konsentrasi Belajar}

\begin{tabular}{llll} 
No & Indikator & Nomor butir pernyataan & Jumlah \\
\hline 1 & Perhatian & $6,7,10,11,12,18$ & $\mathbf{6}$ \\
\hline 2 & Pemahaman & $1,2,3,20,25,28$ & $\mathbf{6}$ \\
\hline 3 & Keaktifan & $4,8,16,17,22,27$ & $\mathbf{6}$ \\
\hline 4 & Ketelitian & $9,15,19,21,23,30$ & $\mathbf{6}$ \\
\hline 5 & Ketenangan & $5,13,14,24,26,29$ & $\mathbf{6}$
\end{tabular}

Instrumen yang digunakan untuk mengumpulkan data yaitu kuisioner/angket. Kuisioner yang digunakan adalah kuesioner tertutup, yakni kuisioner yang telah disediakan pilihan jawabanya sehingga responden tinggal memilih jawaban sesuai hanya dengan memberi tanda cek pada kolom-kolom jawaban yang telah disediakan (check list).

Pada penelitian ini instrumen yang digunakan untuk pengumpulan data dengan cara memberikan angket kepada validator (pakar, dosen), kemudian angket diberikan ke mahasiswa sebagai subjek uji coba. Adapun yang disajikan dalam deskripsi data ini adalah berupa distribusi frekuensi yang disajikan per indikator beserta presentase frekuensi dan perolehan skor.Adapun prosedur penelitian ini adalah: 


\section{Gambar Prosedur Penelitian}

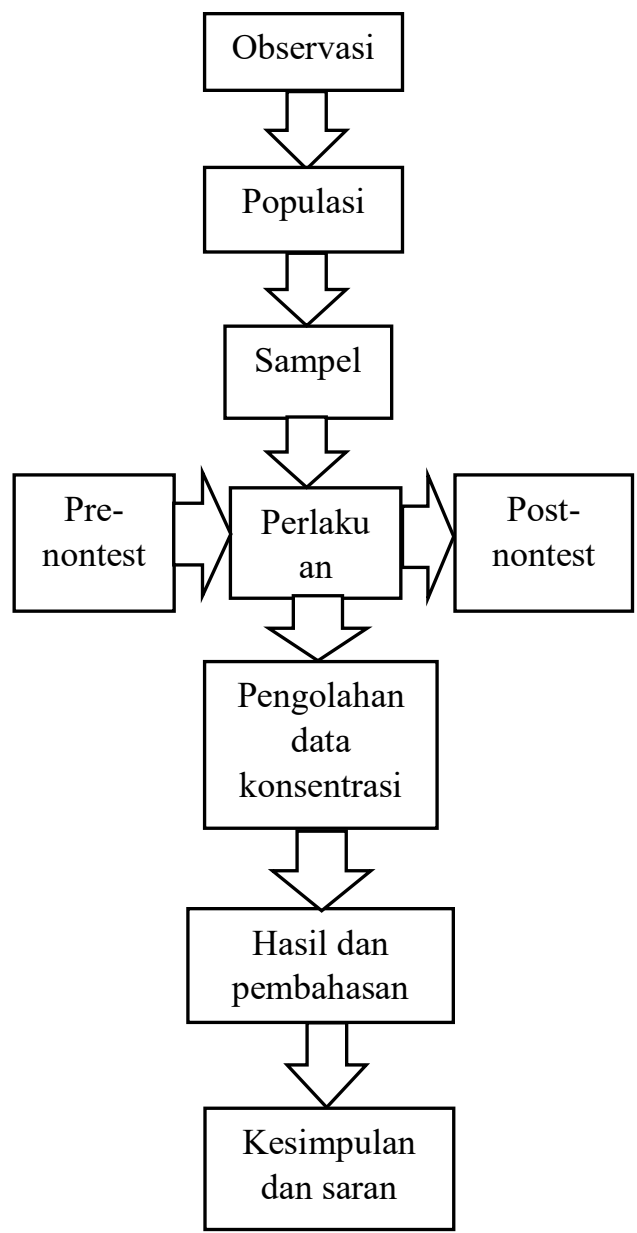

\section{HASIL DAN PEMBAHASAN}

Validasi instrumen yang digunakan dalam penelitian ini adalah angket konsentrasi belajar.Analisis instrumen yang digunakan dalam metode tes adalah uji validitas yang di ujikan ke validator ahli (dosen). Jumlah butir pernyataan 30 butir dan diperoleh 30 butir pernyataan dinyatakan valid sesuai dengan perbaikan.

Pre-nontest yang diberikan kepada mahasiswa dalam bentuk 30 pernyataan dengan kriteria sangat setuju, setuju, tidak setuju, dan sangat tidak setuju.Pre-nontest yang diberikan kepada mahasiswa untuk mengetahui kondisi awal mahasiswa sebelum melakukan perlakuan. Post-nontest yang diberikan kepada mahasiswa untuk mengetahui peningkatan konsentrasi belajarmahasiswa dengan menggunakan media pembelajaran Evaluasi pembelajaran quizizz.

\section{Tabel Statistik Deskriptif}

Deskripsi Pre- Post-




\begin{tabular}{ccc} 
& nontest & nontest \\
\hline $\mathrm{N}$ & 9 & 9 \\
Mean & 60 & 84
\end{tabular}

Berdasarkan tabel 4.1 di atas, diketahui bahwa rata-rata (mean) dari tanggapan mahasiswa terhadap kuesioner pre-nontest yaitu 60 dan skor tersebut cukup. Rata-rata tanggapan mahasiswa pada kuesioner post-nontest adalah 84 dan skor tersebut tergolong baik.Melalui deskripsi data di atas maka dapat dinyatakan bahwa hasil untuk post-nontest cenderung lebih tinggi dari hasil pre-nontest.

Berdasarkan pengolahan data yang dilakukan secara kualitatif diperoleh sebaran yang hampir merata pada seluruh indikator konsentrasi belajar siswa setelah melakukan evaluasi pembelajaran quizizz. Data yang selanjutnya akan dianalisis ditabulasi dalam bentuk histogram. Berikut ini histogram skor pre-nontes dan post-nontest angket konsentrasi belajar mahasiswa:

\section{Gambar Histogram Skor Pre-Nontes dan Post-Nontest} Angket Konsentrasi belajar

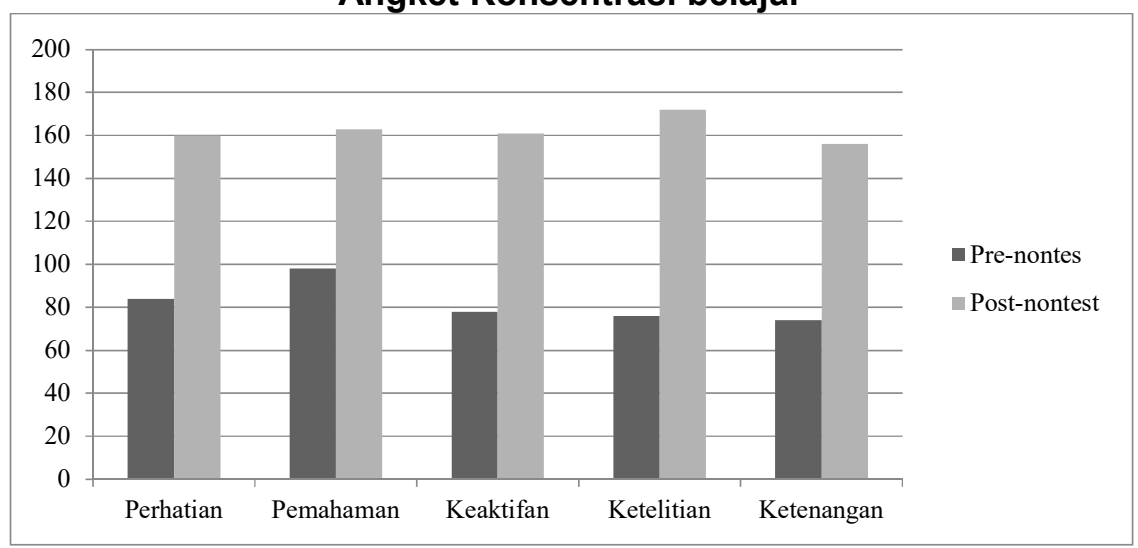

Selain di atas, berikut disajikan skor gain masing-masing indikator pada diagram lingkaran:

\section{Gambar Persentase Perbandingan Uji Gain pada masing-masing Indikator Konsentrasi Belajar Mahasiswa}




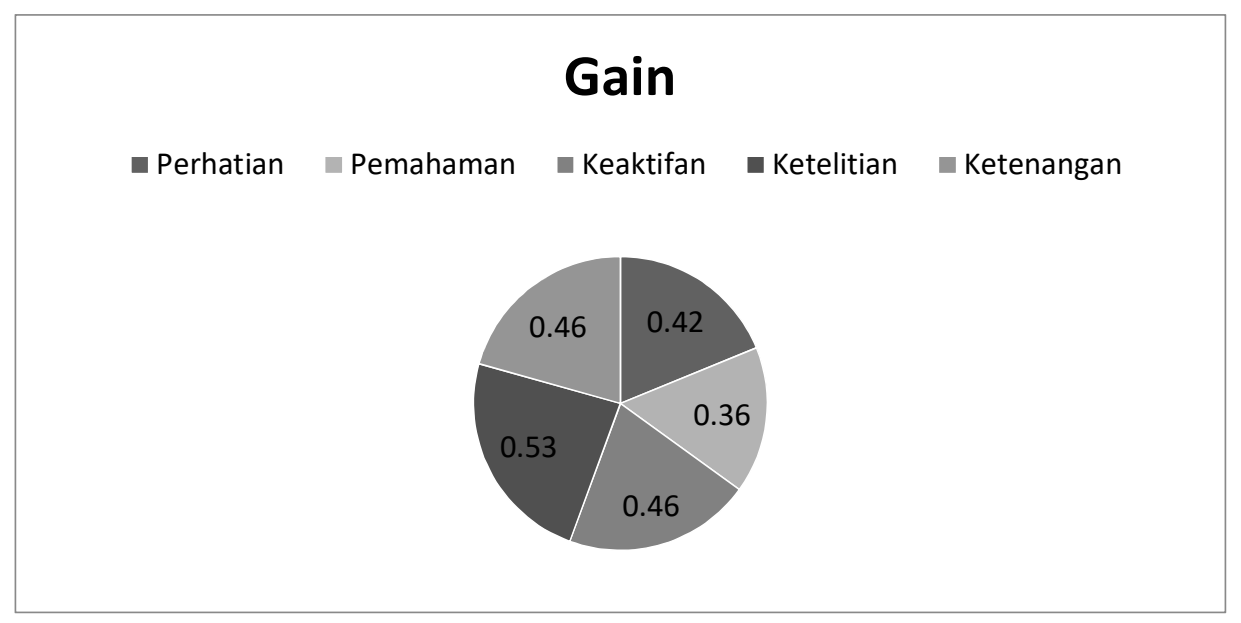

Berdasarkan hasil pengolahan data, peneliti memperoleh informasi bahwa pemanfaatan konsentrasi belajar mahasiswa dapat ditingkatkan dengan melakukan evaluasi pembelajaran menggunakan quizizz. Dengan berpedoman pada tabel interpretasi uji gain berikut ini:

\section{Tabel Interpretasi Uji Gain}

\begin{tabular}{cc}
\hline Nilai g & Interpretasi \\
\hline $\mathbf{0 , 7 1 - 1 , 0 0}$ & Tinggi \\
$\mathbf{0 , 3 1 - 0 , 7 0}$ & Sedang \\
$\mathbf{0 - 0 , 3 0}$ & Rendah \\
\hline
\end{tabular}

Seluruh indikator konsentrasi belajar termasuk kategori sedang. Peningkatan paling maksimum adalah indikator ketelitian dengan gain 0,53 dan paling minimum adalah indikator pemahaman dengan gain 0,36.

Hasil wawancara mendalam terhadap mahasiswa terkait masing-masing indikator, mahasiswa mengungkapkan: 1) Perhatian, dengan menggunakan gadget mahasiswa mengakui lebih memperhatikan seluruh langakah dalam mengikuti evaluasi pembelajaran kimia fisika II dengan menggunakan quizizz. 2) Pemahaman, evaluasi yang dilakukan diluar lingkungan kampus mewajibkan mahasiswa memahami soal sendiri, tanpa bantuan mahasiswa lain. 3) Keaktifan, mahasiswa mengungkapkan dengan evaluasi pembelajaran degan menggunakan quizizz mahasiswa lebih aktif untuk membuka kembali seluruh catatan dan buku yang mahasiswa miliki. 4) Ketelitian, Penggunaan aplikasi quizizz menuntut ketelitian karena dibatasi oleh waktu. 5) Ketenangan, pada indikator terakhir ini mahasiswa tidak mau buru-buru mengerjakan karena mahasiswa mengaku takut saat mahasiswa menjawab kemudian respon hasil yang diterima oleh mahasiswa. 
Secara keseluruhan, hasil uji gain konsentrasi belajar mahasiswa Pendidikan Kimia FKIP-UKI melalui pemanfaatan evaluasi pembelajaran quizizz pada mata kuliah Kimia Fisika I sebesar 0,45 dengan interpretasi sedang.

\section{KESIMPULAN DAN SARAN}

Berdasarkan analisis hasil dan pembahasan dapat ditarik kesimpulan bahwa pemanfaatan evaluasi pembelajaran quizizz pada mata kuliah Kimia Fisika I meningkatkan konsentrasi belajar mahasiswa pendidikan kimia FKIP-UKI..Peningkatan konsentrasi belajar kimia mahasiswasebesar 0,45 dengan kategori sedang.

Saran bagi dosen yang akan menggunakan media Evaluasi pembelajaran quizizz harus mampu membuat evaluasi pembelajaran quizizz tersebut dan mengetahui terlebih dahulu cara menggunakannya.Bagi peneliti selanjutnya, evaluasi pembelajaran quizizz dapat menggunakan materi yang berbeda dan untuk memperoleh hasil maksimal, sebaiknya peneliti pada saat pemberian pre nontest memastikan mahasiswa untuk memberikan jawaban sejujurnya tanpa ada interfensi dari pihak manapun. Bagi mahasiswa, menggunakan media evaluasi pembelajaran quizizz dalam proses pembelajaran saat prakter kerja mengajar (PKM) dan setelah menjadi guru. Bagi UKI, agar memfasilitasi mahasiswa dengan pembelajaran yang sesuai dengan tuntutan revolusi industri 4.0

\section{ACUAN PUSTAKA}

Darmaningrat, E. W. (2018). Pemanfaatan Aplikasi Digital Learning pada Pembelajaran Pengayaan Di Sekolah Menengah Kota Surabaya. Surabaya: Seminar Nasional Sistem Informasi Indonesia.

Hamalik, Oemar. (2004). Proses Belajar Mengajar. Jakarta: Bumi Aksara.

Hamida, Naba, dkk. (2011). Studi Komparasi Penggunaan Laboratorium Virtual dan Laboratorium Riil Dalam Pembelajaran Student Teams Achievement Division (STAD) Terhadap Prestasi Belajar Ditinjau dari Kreativitas Mahasiswa Pada Materi Pokok Sistem Koloid Kelas XI Semester Genap SMA Negeri 1 Banyudono Tahun Pelajaran 2011/2012. Jurnal Pendidikan Kimia Universitas Sebelas Maret. ISSN: 2337-9995. Vol.2 No.2 Tahun 2013. (Diakses 10 Juli 2014)

Hasanah, N. (2014). Konsentrasi Belajar Pada Kegiatan Origami Dengan Menggunakan Metode Demonstrasi Pada Anak Kelompok B Di Tk Aba Gedongkiwo Kecamatan Mantrijeron Yogyakarta. Yogyakarta: Universitas Negeri Yogyakarta.

Menteri riset, teknologi, dan pendidikan tinggi republik indonesia. (2015, desember 28).tentang standar nasional pendidikan tinggi. Peraturan menteri riset, teknologi, 
dan pendidikan tinggi republik indonesia nomor 44. Jakarta, dki, indonesia: kemenristekdikti

Nana Sudjana.(2004). Dasar-Dasar Proses Belajar Mengajar. Bandung: Sinar Baru Algensindo.

Purba, L. S. L. (2017). Pengaruh Penerapan Model Pembelajaran Kooperatif Tipe Two StayTwo Stray (TS-TS) terhadap Hasil Belajar dan Aktivitas Belajar Mahasiswa pada Pokok Bahasan Koloid. EduMatSains, 1(2), 137-152.

Rachman.(2010). Teori Konsentrasi Belajar. Diakses dari http://repository.upi/s_tb_055186_bab_ii.pdf/.Pada tanggal 6 Maret 2019 pukul 12.32 WIB.

Sugandi, Ahmad. (2004). Teori Pembelajaran. Semarang: UPT MKK UNNES

Suo Yan mei, S. Y. (2018). Implementing Quizizz as Game Based Learning in the Arabic Classroom. Journal of Social Sciences Education and Research, 208-212.

Sugiyono. (2014). Metode Penelitian Pendidikan Pendekatan Kuantitatif, Kualitatif, dan R\&D. Bandung: Alfabeta.

Warsita, Bambang. (2008). Teknologi Pembelajaran: Landasan \& Aplikasinya, Jakarta : Rineka.

Wilson, J.P. (2001). Drug Information. Edition 209-231. New York: McGraw-Hill. 